\title{
Auditing Carotid Endarterectomy: A Regional Experience
}

\author{
J. Max Findlay, Linda Nykolyn, Tracey B. Lubkey, John H. Wong, \\ Mikael Mouradian, Ambikaipakan Senthilselvan
}

\begin{abstract}
Background: Proof from randomized controlled trials that carotid endarterectomy (CEA) is efficacious in stroke prevention has resulted in a large resurgence of its use in recent years. We wished to determine if patients in our region were being selected and treated with complication rates consistent with the randomized trials. Methods: We have completed four audits of CEAs performed in our region since 1994, each followed by feed-back of results to the participating surgeons. Operations for $>70 \%$ symptomatic stenosis were considered appropriate, those for 50\%-69\% symptomatic and $>60 \%$ asymptomatic stenosis were considered uncertain and all others, including those in medically or neurologically unstable patients, were designated inappropriate. In part 4 , the referral source and nature of the patients was also determined. Results: Part 1 (April 1994 - September 1995) found that of 291 CEAs performed 33\% were appropriate, $48 \%$ were uncertain and $18 \%$ were inappropriate, and $40 \%$ of patients who underwent CEA were asymptomatic. In part 2 (September 1996 - September 1997) appropriate indications significantly improved to $49 \%$ of 184 CEAs (P=0.005), uncertain indications remained nearly the same at $47 \%$, inappropriate indications fell to $4 \%$ ( $\mathrm{P}=0.00002$ ), and asymptomatic patients remained at $40 \%$. The results of part 3 (October 1997 - October 1998) remained nearly the same as part 2 (249 CEAs, $47 \%$ appropriate, 51\% uncertain, $2 \%$ inappropriate, $45 \%$ asymptomatic). Part 4 (October 1999 - October 2000) results were significantly better than part 3, appropriate indications increasing from $47 \%$ to $58 \%$ of 222 CEAs ( $\mathrm{P}=0.02)$, and an elimination of inappropriate operations $(\mathrm{P}=0.03)$. Stroke and death complications declined over the study period from an overall rate of $5.2 \%$ in part 1 to $2.3 \%$ in part 4 . In part 4 the majority of patients $(69 \%)$ were referred to surgeons directly from general practitioners, including $58(73 \%)$ of the 80 asymptomatic patients who underwent CEA. Interpretation: Regular auditing and feedback of results and information to surgeons has resulted in significant and continued improvements in the surgical performance of CEAin our region. Since the majority of patients are referred directly to surgeons by general practitioners, it is important that this group of physicians be familiar with current CEA guidelines.
\end{abstract}

RÉSUMÉ: Évaluation de l'endartérectomie carotidienne: une expérience régionale. Introduction: La preuve basée sur des études contrôlées randomisées que l'endartérectomie carotidienne (EAC) est efficace dans la prévention de l'accident vasculaire cérébral a entraîné une augmentation importante de son utilisation ces dernières années. Nous voulions déterminer si le taux de complications en relation avec le choix et le traitement des patients de notre région était comparable à celui des études randomisées. Méthodes: Nous avons complété 4 évaluations d'EACs effectuées dans notre région depuis 1994, chacune étant suivie de la communication des résultats aux chirurgiens participants. Les chirurgies effectuées pour des sténoses symptomatiques de plus de $70 \%$ étaient considérées comme appropriées, celles effectuées pour des sténoses symptomatiques de 50\% à $69 \%$ et pour des sténoses asymptomatiques de plus de $60 \%$ étaient considérées comme incertaines et toutes les autres, incluant celles effectuées chez des patients instables au point de vue neurologique étaient considérées comme inappropriées. Dans la quatrième partie, la source de référence et la nature des patients étaient également examinées. Résultats: La première partie de l'étude (avril 1994 à septembre 1997) a montré que, des 291 EACs, 33\% étaient appropriées, 48\% étaient incertaines et 18\% étaient inappropriées. 40\% des patients qui ont subi une EAC étaient asymptomatiques. Dans la deuxième partie (septembre 1996 à septembre 1997), le taux d'indications appropriées s'est amélioré significativement, soit $49 \%$ de 184 EACs $(\mathrm{P}=0,005)$, celui des indications incertaines est demeuré pratiquement le même, soit $47 \%$, celui des indications inappropriées est tombé à $4 \%(\mathrm{P}=0,00002)$ et le taux de patients asymptomatiques est resté à $40 \%$. Les résultats de la troisième partie (octobre 1997 à octobre 1998) sont demeurés pratiquement les mêmes que pendant la deuxième partie (249 EACs, $47 \%$ appropriées, $51 \%$ incertaines, $2 \%$ inappropriées, $45 \%$ asymptomatiques). Les résultats de la quatrième partie (octobre 1999 à octobre 2000) étaient significativement améliorés par rapport à ceux de la troisième partie. Cependant, les indications appropriées ont augmenté de $47 \%$ à $58 \%$ de 222 EACs $(\mathrm{P}=0,02)$ et on a observé une élimination des chirurgies inappropriées $(\mathrm{P}=$ 0,03). Les accidents vasculaires cérébraux et les décès découlant de la chirurgie ont diminué au cours de la période de l'étude, le taux étant passé de 5,2\% dans la première partie à $2,3 \%$ dans la quatrième. Dans la quatrième partie, la majorité des patients $(69 \%)$ étaient référés aux chirurgiens directement par les généralistes, dont $58(73 \%)$ des 80 patients asymptomatiques qui ont subi une EAC. Interprétation: Une évaluation régulière et une communication des résultats aux chirurgiens a entrainé une amélioration significative et soutenue du succès chirurgical de l'EAC dans notre région. Comme la majorité des patients sont référés directement aux chirurgiens par les généralistes, il est important que ce groupe de médecins soit familier avec les lignes directrices sur l'EAC.

Can. J. Neurol. Sci. 2002; 29: 326-332

Studies and commentaries from the 1980s expressing concern about the efficacy, appropriateness, and complications of carotid endarterectomy (CEA), ${ }^{1-8}$ were followed by a series of multicenter randomized controlled trials comparing CEA to medical treatment alone. Reported throughout the 1990s, these studies validated the use of CEAunder certain circumstances, ${ }^{9-15}$ and led to a rapid and large resurgence in the use of CEA in
From the Division of Neurosurgery, University of Alberta, Clinical Quality Resource and Risk Management Department, Capital Health Authority (JMF, LN, TBL), Division of Neurosurgery, University of Calgary (JHW), Division of Neurology, University of Alberta (MM), Epidemiology Program, Department of Public Health, University of Alberta (AS), Alberta, Canada.

ReCeIVED JANUARY 16, 2002. ACCePTED INFinalform APRiL 25, 2002. Reprint requests to: J. Max Findlay, Division of Neurosurgery, Department of Surgery, Clinical Professor, University of Alberta, 2D1.02 WMHSC, 8440 - 112 Street, Edmonton, Alberta, Canada T6G 2B7 
North America. ${ }^{16-19}$ Patients in the randomized trials were selected, carotid stenosis was measured in a standardized fashion and treatment complications were carefully monitored and reported. Because we were uncertain patients undergoing CEAin our community in the wake of these trials were being selected with comparable criteria and treated with similar complication rates, in 1994 we began examining the appropriateness and complications of CEA performed in our region.

Our first retrospective review of 291 consecutive CEAs found that almost one in five patients in our community underwent CEA inappropriately, and half had uncertain indications. ${ }^{20}$ The stroke and death rate among patients undergoing CEA for asymptomatic stenosis in our region was unacceptably high. Following distribution of these disturbing results to our carotid surgeons along with practice guidelines and notification of a prospective audit to follow, the performance of CEA in our region improved considerably. ${ }^{21}$ The rate of inappropriate operations fell from $18 \%$ to $4 \%$, the rate of appropriate operations increased from $33 \%$ to $49 \%$, and the complication rate in patients without symptoms fell from $5.1 \%$ to $2.7 \%$. It appeared that education and surveillance could significantly improve the use and performance of this procedure.

Two additional retrospective CEA audits have since been carried out in our region, and the results are presented here. The objectives have been to remeasure the performance of CEA in our region when monitoring is periodic and the results reported back to the operating surgeons. In our last audit, we also wished to track the nature and referral source of patients undergoing CEA.

\section{SUBJECTS AND METHODS}

The first retrospective study of all CEAs performed in Edmonton, Alberta, Canada examined patients treated between April 1994 and September $1995,{ }^{20}$ the second prospective study followed those treated between September 1996 and September $1997,{ }^{21}$ the third retrospective audit reviewed those treated between October 1997 and October 1998, and the most recent retrospective audit covered October 1999 to October 2000. During this six year period Edmonton has had three tertiary care teaching hospitals, which are the only hospitals in which CEAs are performed in Northern Alberta, serving a population of about 1.6 million people from a large geographic area including part of northern British Columbia, the Yukon, and Nunavut. Surgeons performing CEA during this period have remained largely the same; one surgeon relocated out of country following the first audit and one new surgeon was included in the last audit. The 10 surgeons enrolled in this study are from neurosurgical, general surgery and vascular surgery services.

In the first audit (part 1 of the study) hospital chart and radiographic study reviews as well as follow-up patient or family telephone interviews at least 30 days from surgery were performed by physicians (JHWand JMF). In the following three audits (parts 2-4 of the study) information was collected by a nurse familiar with cerebrovascular disease who was associated with and employed by the regional Clinical Quality Resource and Risk Management Department. Patient demographic information, radiological reports, operative indications, surgical results and complications, resource utilization indices (hospital lengths of stay, special care unit admissions) were recorded in a computer database (Access 97, Microsoft Corporation). Patients were considered symptomatic from their carotid stenosis if there was a documented history of prior ipsilateral retinal or hemispheric ischemia. Patients without such ipsilateral, lateralizing neurological symptoms, including those with nonspecific complaints such as dizziness or cognitive impairment, and those in whom carotid stenosis was found incidentally or due to the presence of a carotid bruit were considered asymptomatic. In part 4 , the source and method of referral for surgery was also determined.

For each patient, the appropriateness of surgery was classified on the basis of the results of randomized controlled trials studying $\mathrm{CEA}^{9-15}$ and according to clinical practice guidelines established by the Canadian Neurosurgical Society ${ }^{22}$ (Table 1). These criteria were used in conjunction with angiographic stenoses as recorded in the radiologists' reports as well as remeasurement values of carotid narrowing done as part of the first two audits. In parts 1 and 2 there was substantial concordance between the radiologists' reported degrees of stenosis and the remeasurement values, and in parts 3 and 4 the correlation was reconfirmed by remeasuring 20 randomly selected angiograms $(\mathrm{K}=0.80)$. Appropriateness assignment was therefore based on radiologist reports only, best reflecting real clinical practice. Carotid endarterectomy was considered appropriate for patients with symptomatic carotid stenoses $\geq 70 \%$. Uncertain indications for surgery were for those patients with symptomatic stenoses $<70 \%$ or asymptomatic stenoses $\geq 60 \%$. Patients were judged to have an inappropriate indication for surgery if they had an asymptomatic carotid stenosis $<60 \%$ or if they were neurologically or medically unstable before CEA. Neurologically unstable patients were those who underwent surgery in the setting of a progressive neurological deficit or those who underwent surgery within one day of a fixed neurological deficit. ${ }^{23}$ High-risk preoperative medical conditions were unstable angina (defined as angina at rest or of new onset), myocardial infarction within three months before CEA, or uncontrolled congestive heart failure.

Hospital charts were reviewed and follow-up telephone interviews of all discharged patients were conducted to detect the development of complications following CEA. The primary outcome was postoperative stroke, defined as the onset of a new neurological deficit (unrelated to cranial nerve injury) lasting $>24$ hours, or death within 30 days of surgery. Secondary outcomes were myocardial infarction or unstable angina, congestive heart failure, atrial fibrillation, and neck hematoma.

Part 1 was a retrospective review of hospital records and $\mathrm{x}$ rays combined with patient follow-up by telephone. Part 2 was prospective and followed the circulation of the first audit results to all surgeons performing CEA in our city along with clinical practice guidelines for the use of CEA, ${ }^{22}$ educational rounds at the participating hospital, and notification that surveillance of this procedure was to resume. The results of this second audit were also mailed to the surgeons involved in the study, but prospective monitoring was discontinued. Parts 3 and 4 were retrospective reviews, the results of which were reported back to the individual surgeons performing CEAin our region.

The Edmonton (Capital Health) Regional Health Research Ethics Board approved the conduct of these audits and this study. Variables were coded dichotomously and analyzed with 
Table 1: Comparison of Part 1 (retrospective), Part 2 (prospective), Part 3 (retrospective) and Part 4 (retrospective) Audits of Carotid Endarterectomy

\begin{tabular}{|c|c|c|c|c|c|}
\hline Number of CEAs & $\begin{array}{l}\text { Part } 1(n=291) \\
\text { Apr } 1994- \\
\text { Sep } 1995\end{array}$ & $\begin{array}{l}\text { Part } 2(n=184) \\
\text { Sep } 1996- \\
\text { Sep } 1997\end{array}$ & $\begin{array}{l}\text { Part } 3(n=249) \\
\text { Oct } 1997- \\
\text { Oct } 1998\end{array}$ & $\begin{array}{l}\text { Part } 4(n=222) \\
\text { Oct } 1999 \text { - } \\
\text { Oct } 2000\end{array}$ & $\begin{array}{l}\text { P value (Part } 3 \\
\text { vs. Part 4)* }\end{array}$ \\
\hline Mean age (years) & $67.8 \pm 0.5$ & $66.7 \pm 1.0$ & $70.0 \pm 1.0$ & $69.7 \pm 1.0$ & \\
\hline Symptomatic & $174(60 \%)$ & $110(60 \%)$ & $136(55 \%)$ & $142(64.0 \%)$ & 0.04 \\
\hline Asymptomatic & $117(40 \%)$ & $74(40 \%)$ & $113(45 \%)$ & $80(36.0 \%)$ & 0.14 \\
\hline
\end{tabular}

\begin{tabular}{|c|c|c|c|c|c|}
\hline \multicolumn{6}{|l|}{ Appropriateness of CEA } \\
\hline \multicolumn{6}{|l|}{ Appropriate indication } \\
\hline$\cdot \geq 70 \%$ symptomatic & $92(33 \%)$ & $88(49 \%)$ & $116(47 \%)$ & $128(57.7 \%)$ & 0.02 \\
\hline Uncertain indication & $138(49 \%)$ & $84(47 \%)$ & $127(51 \%)$ & $94(42.3 \%)$ & 0.06 \\
\hline$\cdot \geq 60 \%$ asymptomatic & $75(27 \%)$ & $64(36 \%)$ & $107(43 \%)$ & $80(36.0 \%)$ & 0.13 \\
\hline Inappropriate indications & $51(18 \%)$ & $8(4 \%)$ & $6(2 \%)$ & 0 & 0.03 \\
\hline$\bullet<60 \%$ asymptomatic & $37(13 \%)$ & $8(4 \%)$ & $6(2 \%)$ & 0 & 0.03 \\
\hline \multicolumn{6}{|l|}{ In-Hospital/30 Day Stroke orDeath Rate } \\
\hline Overall & $5.2 \%$ & $4.9 \%$ & $4.4 \%$ & $2.3 \%$ & 0.2 \\
\hline Symptomatic & $5.2 \%$ & $6.4 \%$ & $6.6 \%$ & $2.1 \%$ & 0.07 \\
\hline Asymptomatic & $5.1 \%$ & $2.7 \%$ & $5.9 \%$ & $2.5 \%$ & 1.0 \\
\hline General/Vascular Surgeons & $5.9 \%$ & $4.9 \%$ & $3.0 \%$ & $2.7 \%$ & 0.23 \\
\hline
\end{tabular}

*Level of significance of univariate analysis determined in the comparison of parts 3 and 4 for each category (difference between parts 1 and 2 are discussed in the results, and there were no significant differences between parts 2 and 3 ).

univariate techniques, chi-square tests were used to compare parts 3 and 4 results, except when the expected values were less than 5 in which case Fisher's exact tests were used. Level of significance was set at a $\mathrm{P}$ value $<0.05$.

\section{RESUlts}

The results of parts 1 and 2 have been previously published, ${ }^{21,22}$ and the main results are included here for comparison with the results of parts 3 and 4 (Table 1). A total of 946 CEAs were reviewed in 894 different patients, and for the 52 patients that underwent staged, bilateral CEAs, each procedure was considered separately for the analysis. All patients were followed for at least 30 days. The mean patient age and gender distribution in all four audits was similar (Table 1). Men, towards the end of their seventh decade of life, predominated.

In part 4 of this study, 10 patients who underwent CEAwere reviewed but excluded from further analysis because they underwent surgery on the basis of carotid ultrasound information and without preoperative cerebral angiography. The number of procedures performed by individual surgeons ranged widely in each audit; from 3-30 in the third audit and from 6-53 in the fourth. Two surgeons in parts 3 and 4 performed less than 10 CEAs in total but the majority (more than one-half) performed more than 20. The number of procedures done by general or vascular surgeons and the number done by neurosurgeons were, respectively, 169 and 122 in part 1, 103 and 81 in part 2, 119 and 130 in part 3, and 149 and 73 in part 4.

The appropriateness of CEA was determined for the patient population in each audit and the results are summarized in Table 1. In part 1, appropriate indications for CEAwere found in $33 \%$ of patients $(92 / 281)$, whereas $49 \%$ had indications considered uncertain (138/281), and inappropriate surgical indications were found in $18 \%$ of patients $(51 / 281)$. In part 2 , after informing the surgeons of the results of part 1 and plans to resume monitoring, $49 \%$ had appropriate indications for CEA (88/184), $47 \%$ had uncertain indications (84/184), and 4\% underwent surgery inappropriately (8/184). The rate of appropriate indications improved significantly compared with results of the first audit ( $33 \%$ to $49 \%, \mathrm{P}=0.0005$ ), the inappropriate use of CEAdropped significantly from $18 \%$ to $4 \%$ ( $\mathrm{P}=0.0002)$, and the rate of CEAs for uncertain indications remained nearly the same $(49 \%$ of CEAs in the first audit and $47 \%$ in the second).

In part 3 appropriate indications for CEA were found in $47 \%$ of patients (116/249), uncertain indications in 51\% (127/249), and inappropriate CEAs were performed in $2 \%(6 / 249)$; these results did not differ significantly from part 2 . However, in part 4 , the rate of appropriate operations improved significantly from part 3 , from $47 \%$ to $58 \%(128 / 222, \mathrm{P}=0.02)$, and inappropriate operations fell from $2 \%$ in part 3 to $0 \%(\mathrm{P}=0.03)$. Also, uncertain 
indications fell from $51 \%$ in part 3 to $42 \%$ (94/222), p=0.06).

In part $1,73 \%(37 / 51)$ of inappropriate CEAs were for asymptomatic stenosis less than $60 \%$, and the remaining 14 patients were either medically or neurologically unstable at the time of surgery. In part 2 and 3 audits, inappropriate CEAs were all for $<60 \%$ asymptomatic stenosis.

The majority of uncertain indications for CEA in each part were patients with asymptomatic stenosis $(27 \%-43 \%$ of patients in each audit). In every part just over one-half of the patients of this subgroup without carotid symptoms had either higher-grade $(\geq 80 \%)$ ipsilateral stenosis or a contralateral carotid occlusion (data not shown).

The stroke or death rates for each part is also shown in Table 1. The overall stroke and death rate has declined over time from $5.2 \%$ to $2.3 \%$. A notable drop from $5.1 \%$ in part 1 to $2.7 \%$ in part 2 was noted for asymptomatic patients, and another from $6.6 \%$ to $2.1 \%$ for symptomatic patients was found between parts 3 and 4. There was a broad range of stroke or death rates among the different surgeons in each part: $0 \%$ to $33 \%$ in the first, $0 \%$ to $17 \%$ in the second, $0 \%$ to $10 \%$ for the third and 0 to $17 \%$ in the fourth. The extremes came from surgeons performing relatively fewer CEAs. The relatively small number of operations performed by a large number of surgeons prevented any statistical association between surgeons or number of CEAs performed by a single surgeon with complication rates. When stratified according to surgical specialty, the difference in stroke or death rate noted between general and/or vascular surgeons versus neurosurgeons was not significant (Table 1).

The referral nature and source of patients undergoing CEA was investigated in part 4 and the results shown in Table 2 . The majority, $69 \%$, were referred by general practitioners directly to carotid surgeons and $14 \%$ were referred by neurologists. It was found that $60 \%$ of the asymptomatic patients who underwent CEA (48/80) had carotid stenosis detected through medical work-up, i.e. the presence of a carotid bruit that led to a carotid Doppler investigation (although it could not be determined in the chart review that a carotid bruit initiated investigations in every instance). Another 23\% (18/80) underwent CEA for an asymptomatic stenosis found incidentally on the side opposite a carotid stenosis or occlusion that had caused cerebral ischemia, $13 \%(11 / 80)$ had neurological symptoms not referable to the carotid system (such as dizziness or syncope) that led to carotid investigations and, in $4 \%$ of asymptomatic patients (3/80), it could not be determined what led to the discovery of carotid stenosis. Fifty-eight of the 80 asymptomatic patients (73\%) in part 4 were referred for surgery by family physicians, the majority (69\%) following the investigation of a carotid bruit.

\section{DISCUSSION}

News from randomized controlled trials in the early 1990s led to a prompt and substantial increase in the number of CEAs performed in North America, although several studies documenting this trend observed that patients were not being selectively referred to high-volume, low-mortality surgeons or centers. ${ }^{17,24}$ Another study following the rise in CEA procedures found that perioperative mortality rates were higher than those reported by the trials. ${ }^{18}$ Our own first audit of CEAperformance in Edmonton (part 1 of this report) found a high rate of inappropriate operations (18\%) and an unacceptably high stroke
Table 2: Source and Cause of Referral for Carotid Endarterectomy: Part 4

\begin{tabular}{lc}
\hline Referral Source $(\mathbf{n}=\mathbf{2 2 2})$ & \\
General Practitioner & $153(68.9 \%)$ \\
Neurologist & $31(14.0 \%)$ \\
Surgeon & $20(9.0 \%)$ \\
Cardiologist & $7(3.1 \%)$ \\
Internist & $6(2.7 \%)$ \\
Emergency Physician & $5(2.3 \%)$
\end{tabular}

Cause forReferral, all patients $(n=222)$

Transient ischemic attack

$97(43.7 \%)$

Minor stroke

$45(20.3 \%)$

Asymptomatic, Detected through medical work-up

$48(21.6 \%)$

Asymptomatic stenosis opposite symptomatic stenosis $\quad 15(6.7 \%)$

Asymptomatic stenosis opposite symptomatic occlusion $3(1.4 \%)$

Asymptomatic, Non-carotid neurological symptoms $\quad 11(4.9 \%)$

Asymptomatic, Uncertain

$3(1.4 \%)$

Cause for Referral from General Practitioners (n=153)

Transient ischemic attack

$73(47.7 \%)$

Minor stroke

$22(14.4 \%)$

Detected through medical work-up

$40(26.1 \%)$

Asymptomatic stenosis opposite symptomatic stenosis $\quad 5(3.3 \%)$

Asymptomatic stenosis opposite symptomatic occlusion $2(1.3 \%)$

Non-carotid neurological symptoms

$9(5.9 \%)$

Uncertain

$2(1.3 \%)$

or death rate among patients undergoing CEAfor asymptomatic stenosis $(5.1 \%)$. It appeared that CEA, a procedure proven efficacious in randomized trials, was growing over-popular through extrapolation of trial results to patients and settings not fully supported by those trials and by surgeons who did not match the operative complication rates in the trials. Appeals for mandatory local audits were made. ${ }^{22,25,26}$

The process of auditing, education and feedback to surgeons has been effective in improving the performance and outcomes of CEA in our region, ${ }^{21}$ and in a similar state-wide project in Iowa. ${ }^{27}$ Our region's results have improved significantly over time, both in terms of appropriateness of surgery and lowering of major complication rates. The most impressive improvements have been in the increased number of patients undergoing surgery for the clearest indication for CEA, symptomatic severe stenosis, and the elimination of inappropriate operations. The most recent audit demonstrated a slight decline in surgeries for asymptomatic stenosis, although this more controversial indication was still found in $36 \%$ of patients.

While the definition of "appropriate" and "inappropriate" indications for CEA in our analysis causes little argument, the assignment of asymptomatic carotid stenosis and moderate, 50$69 \%$ symptomatic stenosis as "uncertain" indications for CEAis the source of controversy. Two randomized controlled trials found that CEAbenefited patients without carotid symptoms. In the first, which compared 233 veterans (all men) in the medical group to 211 in the surgical group over about four years, found a 
significant difference in favor of surgery only when transient ischemia was included as an outcome event (when just stroke and death were considered only a trend favoring surgery was apparent). ${ }^{11}$ In the larger Asymptomatic Carotid Atherosclerosis Study (ACAS) a total of 1662 patients were randomized to either CEA or medical treatment, and after following the patients for about $2 \frac{1}{2}$ years it was calculated that CEA lowered the risk of stroke or death over five years from $11.0 \%$ to $5.1 \%(\mathrm{P}=0.004)$ for stenoses between $60 \%-99 \%{ }^{13}$ The benefit did not appear to apply to women, major strokes were not prevented, and a striking aspect of the trial was the very low (less than 2\%) operative stroke or death rate in the surgical group. It has been argued that despite the overall results of ACAS being statistically significant in favor of surgery for asymptomatic stenosis, the clinical significance is marginal, ${ }^{28}$ and only applies if very low perioperative complication rates can be provided. It has been calculated that in order to prevent a single stroke over two years, 67 asymptomatic patients need to undergo CEA, and to prevent one stroke over five years, 17 patients require the procedure. ${ }^{29}$

While the natural history of asymptomatic carotid atherosclerosis appears to be relatively benign overall, there may be additional risk factors that increase the risk of ipsilateral stroke. While not observed in ACAS, observations from the North American Symptomatic Carotid Endarterectomy Trial (NASCET) and the European Carotid Surgery Trial (ECST) indicate the stroke-risk increases with the degree of carotid narrowing, and is as high as $18.5 \%$ over five years for angiographic stenosis between $75 \%$ and $94 \% .{ }^{30,31}$ There is some evidence that the presence of ipsilateral brain infarction on CTor MRI, ${ }^{31-33}$ and plaque ulceration ${ }^{34-38}$ may indicate an increased risk of stroke. Other less well-substantiated risk factors that might worsen the natural history of asymptomatic stenosis include the presence of an occluded contralateral carotid artery, ${ }^{39}$ progressive stenosis ${ }^{40}$ a "soft" or echolucent plaque or evidence of intraplaque hemorrhage on ultrasound. ${ }^{40-43}$ Another logical proposal is that greater benefit will accrue for younger patients ( $\leq 55$ years) undergoing surgery for asymptomatic stenosis. ${ }^{44}$

The situation for moderate, $50 \%-69 \%$ symptomatic stenosis is similar to asymptomatic stenosis. While an overall benefit was conferred by CEA in the group of moderate stenosis symptomatic patients in NASCET, the benefit was substantially less than for higher grade stenosis. ${ }^{15}$ The ipsilateral stroke rate for patients with $50 \%$ to $69 \%$ stenosis over five years was $22.2 \%$ for medically treated patients and $15.7 \%$ for surgically treated patients $(\mathrm{P}=0.045)$, corresponding to an absolute risk reduction of $6.5 \%$. Fifteen patients with moderate symptomatic stenosis require CEA to prevent one ipsilateral stroke at five years. ${ }^{15}$ Further analysis identified four characteristics associated with greater long-term benefit of surgery in patients with moderate stenosis: male sex, recent stroke, recent hemispheric symptoms, and taking $650 \mathrm{mg}$ or more of aspirin per day. ${ }^{15}$

The creation of an "uncertain" category in the appropriateness criteria we have used allows for these two groups of patients, those who are asymptomatic and those symptomatic with moderate stenosis, where the benefit of surgery is more modest, appears to vary according to individual risk factors, and depends particularly on the provision of low complication rates by the operating surgeon. In our study, the majority of "uncertain" CEA patients were asymptomatic, making up nearly $40 \%$ of the total number of patients in each audit. It has been estimated that this figure is even higher in other regions. ${ }^{29,45}$ In our study, almost three-quarters of asymptomatic patients were referred for surgery directly by general practitioners. This isn't surprising since $89 \%$ of Canadian neurologists recently surveyed indicated they never or seldom referred patients with asymptomatic stenosis to surgeons, ${ }^{46}$ and the Canadian Stroke Consortium has issued a consensus opposing both CEA and routine screening for asymptomatic stenosis. ${ }^{47}$

Others have taken the position that CEAcan be recommended for selected patients with asymptomatic stenosis, ${ }^{48-53}$ although it must be acknowledged that there is no conclusive evidence currently available that CEA is more beneficial in any specific subgroup of these patients. ${ }^{29}$ In defense of the relatively high rate of CEAs for asymptomatic patients in our own region, we found that roughly one-half had either angiographic stenosis $\geq 80 \%$ or an occluded carotid artery on the opposite side, and that the stroke or death rate in our last three audits has been less than $3 \%$.

Our results nevertheless indicate that the threshold for CEAin asymptomatic patients among surgeons in our region is low, and overuse of CEA for this indication is a concern. This is an important health care issue in view of the high prevalence of carotid atherosclerosis and neck bruits in our aging population. Neck bruits are present in about $4 \%$ of adults, and this proportion more than doubles for those over the age of $75 .^{54,55}$ Neck bruits are an unreliable sign of significant carotid atherosclerosis, since the majority are associated with mild carotid stenosis, and severe stenoses may not have any audible bruit. ${ }^{56}$ Carotid ultrasound examinations of 429 men and 661 women in the Framingham Heart study whose mean age was 75 years revealed at least moderate stenosis $(>25 \%)$ in $44 \%$ of men and $34 \%$ of women, stenosis correlating positively with elevated systolic blood pressure and cholesterol, and cigarette smoking. ${ }^{57}$ It remains unclear when it is appropriate to screen asymptomatic patients with carotid ultrasound to detect stenosis. ${ }^{47}$ Since we found that patients with asymptomatic stenosis are often referred directly to surgeons by family doctors, it is important that this group of physicians know that CEA is not always an appropriate option for patients without carotid symptoms (amaurosis fugax or lateralizing hemispheric deficits). ${ }^{58}$ A number of factors need to be considered before both initiating investigations and referral to a surgeon. For example, there is a tendency for carotid Doppler ultrasound to over-estimate carotid stenosis severity, ${ }^{59}$ and cerebral angiography performed for confirmation of carotid stenosis carries a nearly $1 \%$ risk even in experienced centers. $^{9,13,60}$ Knowledge of the local surgical stroke or death complication rates are also important, although not often available. ${ }^{2,25,26,48-52}$ For family physicians, modifying risk factors for atherosclerosis and educating patients about the symptoms of carotid transient ischemic attacks are equally or more important steps in stroke prevention than obtaining carotid ultrasounds in asymptomatic patients. ${ }^{47,52}$

In conclusion, we have found that regular auditing of surgical indications and results and feedback of that information to surgeons has resulted in significant and continued improvement in the performance of CEA in our region. The high rate of surgeries for asymptomatic stenosis indicates that there exists a relatively low threshold for surgical repair of this type of lesion. Since most patients are referred for surgery directly by general 
practitioners, this group of doctors might benefit most from guidelines for carotid stenosis investigation and treatment.

\section{ACKNOWLEDGEMENT}

The authors thank Ms. Laurie Arneson for expert assistance in the preparation of this paper.

\section{REFERENCES}

1. Easton JD, Sherman DG. Stroke and mortality rate in carotid endarterectomy: 228 consecutive operations. Stroke 1977;8:565568.

2. Fode NC, Sundt TM Jr, Robertson JT, Peerless SJ, Shields CB. Multicenter retrospective review of results and complications of carotid endarterectomy in 1981. Stroke 1986;17:370-376.

3. Dyken ML, Pokras R. The performance of carotid endarterectomy for disease of the extracranial arteries of the head. Stroke 1984;15:948-950.

4. Brott $\mathrm{T}$, Thalinger $\mathrm{K}$. The practice of carotid endarterectomy in a large metropolitan area. Stroke 1984;15:950-955.

5. Warlow C. Carotid endarterectomy: does it work? Stroke 1984;15:1068-1076.

6. Barnett HJ, Plum F, Walton JN. Carotid endarterectomy: an expression of concern. Stroke 1984;15:941-943.

7. Brott TG, Labutta RJ, Kempczinski RF. Changing patterns in the practice of carotid endarterectomy in a large metropolitan area. JAMA1986;255:2609-2612.

8. Winslow CM, Solomon DH, Chassin MR, et al. The appropriateness of carotid endarterectomy. N Engl J Med 1988;318:721-727.

9. North American Symptomatic Carotid Endarterectomy Trial Collaborators. Beneficial effect of carotid endarterectomy in symptomatic patients with high-grade carotid stenosis. N Engl J Med 1991;325:445-453.

10. European Carotid Surgery Trialists' Collaborative Group. MRC European Carotid Surgery Trial: interim results for symptomatic patients with severe (70-99\%) or with mild (0-29\%) carotid stenosis. Lancet 1991;337:1235-1243.

11. Hobson RW, Weiss DG, Fields WS, et al, for the Veterans Affairs Cooperative Study Group. Efficacy of carotid endarterectomy for asymptomatic carotid stenosis. N Engl J Med 1993;328:221-227.

12. Mayberg MR, Wilson SE, Yatsu F, et al, for the Veterans Affairs Cooperative Studies Program 309 Trialist Group. Carotid endarterectomy and prevention of cerebral ischemia in symptomatic carotid stenosis. JAMA1991;266:3289-3294.

13. Executive Committee for the Asymptomatic Carotid Atherosclerosis Study. Endarterectomy for asymptomatic carotid artery stenosis. JAMA1995;273:1421-1428.

14. European Carotid Surgery Trial. Endarterectomy for moderate symptomatic carotid stenosis: interim results from the MRC European Carotid Surgery Trial. Lancet 1996; 347:1591-1593.

15. Barnett HJM, Taylor DW, Eliaziw M, et al, for the North American Symptomatic Carotid Endarterectomy Trial Collaborators. Benefit of carotid endarterectomy in patients with symptomatic moderate or severe stenosis. N Engl J Med 1998;339:1415-1425.

16. Holloway RG Jr, Witter DM Jr, Mushlin AI, et al. Carotid endarterectomy trends in the patterns and outcomes of care at academic medical centers, 1990 through 1995. Arch Neurol 1998;55:25-32.

17. Tu JV, Hannan EL, Anderson GM, et al. The fall and rise of carotid endarterectomy in the United States and Canada. N Engl J Med 1998;339:1441-1447.

18. Hsia DC, Moscoe LM, Krushat WM. Epidemiology of carotid endarterectomy among medicare beneficiaries 1985-1996 update. Stroke 1998;29:346-350.

19. Morasch MD, Parker MA, Feinglass J, Manheim LM, Pearce WH. Carotid endarterectomy: characterization of recent increases in procedure rates. J Vasc Surg 2000;31:901-909.

20. Wong JH, Findlay JM, Suarez-Almazor ME. Regional performance of carotid endarterectomy. Appropriateness, outcomes, and risk factors for complications. Stroke 1997;28:891-898.
21. Wong JH, Lubkey TB, Suarez-Almazor ME, Findlay JM. Improving appropriateness of carotid endarterectomy. Results of a prospective city-wide study. Stroke 1999;30:12-15.

22. Findlay JM, Tucker WS, Ferguson GG, et al. Guidelines for the use of carotid endarterectomy: current recommendations from the Canadian Neurosurgical Society. Can Med Assoc J 1997;157(6):653-659.

23. McCrory DC, Goldstein LB, Samsa GP, et al. Predicting complications of carotid endarterectomy. Stroke 1993;24:12851291.

24. Gross CP, Steiner CA, Bass EB, Powe NR. Relation between prepublication release of clinical trial results and the practice of carotid endarterectomy. JAMA2000;284:2886-2893.

25. Moore WS, Barnett HJM, Beebe HG, et al. Guidelines for carotid endarterectomy: a multidisciplinary consensus statement from the Ad Hoc Committee, American Heart Association. Stroke 1995;26:188-201.

26. Goldstein LB, Moore WS, Robertson JT, Chaturvedi S. Complication rates for carotid endarterectomy. A call to action. Stroke 1997;28:889-890.

27. Kresowik TF, Hemann RA, Grund SL, et al. Improving the outcomes of carotid endarterectomy: results of a statewide quality improvement project. J Vasc Surg 2000;31:918-926.

28. Lanska DJ, Kryscio RJ. Endarterectomy for asymptomatic internal carotid artery stenosis. Neurology 1997;48:1481-1490.

29. Barnett HJM, Eliasziw M, Meldrum HE, Taylor DW. Do the facts and figures warrant a 10-fold increase in the performance of carotid endarterectomy on asymptomatic patients? Neurology 1996;46:603-608.

30. The European Carotid Surgery Trialist Collaborative Group. Risk of stroke in the distribution of an asymptomatic carotid artery. Lancet 1995;345:209-212.

31. Inzitari D, Eliasziw M, Gates $\mathrm{P}$, et al. The cause and risk of stroke in patients with asymptomatic internal carotid artery stenosis. N Engl J Med 2000;342:1693-1700.

32. Norris JW, Zhu CZ. Silent stroke and carotid stenosis. Stroke 1992;23:483-485.

33. Hougaku H, Matsumoto M, Handa N, et al. Asymptomatic carotid lesions and silent cerebral infarction. Stroke 1994;25:566-570.

34. Norris JW, Zhu CZ, Bornstein NM, Chambers BR. Vascular risks of asymptomatic carotid stenosis. Stroke 1992;22:1485-1490.

35. Moore WS, Boren C, Malone JM, et al. Natural history of nonstenotic, asymptomatic ulcerative lesions of the carotid artery. Arch Surg 1978;113:1352-1359.

36. Dixon S, Pais SO, Raivola C, et al. Natural history of nonstenotic, asymptomatic ulcerative lesions of the carotid artery: a further analysis. Arch Surg 1982;117:1493-1498.

37. Autret A, Pourcelot L, Saudea D, et al. Stroke risk in patients with carotid stenosis. Lancet 1987;1:888-890.

38. Weschler LR. Ulceration and carotid artery disease. Stroke 1988;19:650-653.

39. Rutgers DR, Klijn CJM, Kappelle LJ, et al. Sustained bilateral hemodynamic benefit of contralateral carotid endarterectomy in patients with symptomatic internal carotid artery occlusion. Stroke 2001;32:728-734.

40. Liapis CD, Kakisis JD, Kostakis AG. Carotid stenosis: factors affecting symptomatology. Stroke 2001;32:2782-2786.

41. Golledge J, Greenhalgh RM, Davies AH. The symptomatic carotid plaque. Stroke 2000;31:774-781.

42. Block RW, Grey-Weale AC, Mock PA, et al. The natural history of asymptomatic carotid artery disease. J Vasc Surg 1993;17:160171.

43. Reilly LM, Lusby RJ, Hughes L, et al. Carotid plaque histology using real-time ultrasonography. Clinical and therapeutic implications. Am J Surg 1983;146:188-193.

44. Sarasin FP, Bounameaux H, Bogousslavsky J. Asymptomatic severe carotid stenosis: immediate surgery or watchful waiting? A decision analysis. Neurology 1995;45:2147-2153.

45. Karp HR, Flanders WD, Shipp CC, Taylor B, Martin D. Carotid endarterectomy among medicare beneficiaries. A statewide evaluation of appropriateness and outcome. Stroke 1998;29:4652. 
46. Chaturvedi S, Meinke JL, St. Pierre E, Bertasio B. Attitudes of Canadian and US neurologists regarding carotid endarterectomy for asymptomatic stenosis. Can J Neurol Sci 2000;27:116-119.

47. Perry JR, Szalai JP, Norris JW, for the Canadian Stroke Consortium. Consensus against both endarterectomy and routine screening for asymptomatic carotid artery stenosis. Arch Neurol 1997;54:25-28.

48. Moore WS, Barnett HJM, Beebe HG, et al. Guidelines for carotid endarterectomy: a multidiscliplinary consensus statement from the Ad Hoc Committee, American Heart Association. Circulation 1995;91:566-579.

49. Wolf PA, Clagett GP, Easton JD, et al. Preventing ischemic stroke in patients with prior stroke and transient ischemic attack: a statement from healthcare professionals from the Stroke Council of the American Heart Association. Stroke 1999;30:1991-1994.

50. Albers GW, Hart RG, Lutsep HL, Newell DW, Sacco RL. Supplement to the guidelines for the management of transient ischemic attacks: a statement from the Ad Hoc Committee on Guidelines for the Management of Transient Ischemic Attacks, Stroke Council, American Heart Association. Stroke 1999;30:2502-2511.

51. Gorelick PB, Sacco RL, Smith DB, et al. Prevention of a first stroke: a review of guidelines and a multidisclipinary consensus statement from the National Stroke Association. JAMA 1999;281:1112-1120.
52. Sacco RL. Extracranial carotid stenosis. $N$ Engl J Med 2001;345:1113-1118.

53. Kistler JP, Furie KL. Carotid endarterectomy. (Editorial.) N Engl J Med 2000;342:1743-1745.

54. Barnett HJM, Haines SJ. Carotid endarterectomy for asymptomatic carotid stenosis. (Editorial.) New Engl J Med 1993;328:276-278.

55. Van Ruiswyk J, Noble H, Sigmann P. The natural history of carotid bruits in elderly persons. Ann Intern Med 1990;112:340-346.

56. Barnes RW, Robertson JT. Surgical considerations in asymptomatic disease in stroke. Barnett HJM, Mohr JP, Stein BM, Yatsu FM (Eds): 3rd ed. Churchill Livingstone, 1998:1228-1241.

57. Wilson PWF, Hoeg JM, D'Agostino RB, et al. Cumulative effects of high cholesterol levels, high blood pressure, and cigarette smoking on carotid stenosis. N Engl J Med 1997;337:516-522.

58. Feasby TE, Quan H, Ghalis WA. Geographic variation in the rate of carotid endarterectomy in Canada. Stroke 2001;32:2417-2422.

59. Qureshi AI, Suri FK, Ali Z, et al. Role of conventional angiography in evaluation of patients with carotid artery stenosis demonstrated by Doppler ultrasound in general practice. Stroke 2001;32:22872291.

60. Hankey GJ, Warlow CP, Molyneus AJ. Complications of cerebral angiography for patients with mild carotid territory ischemia being considered for carotid endarterectomy. J Neurol Neurosurg Psychiatry 1990;53:542-548. 